\title{
EVALUATION OF DENTAL IMPLANTS IN MANDIBULAR NARROW RIDGES USING BONE EXPANSION AND BENDING TECHNIQUE
}

\author{
Alaa A. Heggy ${ }^{1 *}$ BDS, Ahmed M. Shaaban² PhD, Riham M. El-Dibany² $P h D$
}

\begin{abstract}
INTRODUCTION: Narrow dentoalveolar ridges remain a challenge for the successful placement of implants; success depends largely on the quality and quantity of the available bone in the recipient site. This however may be compromised or unavailable which necessitates the need to manipulate the residual bone by contouring or making dimensional changes to create an intra-bony cavity to form a receptor site for an implant while preserving bone integrity and viability.

OBJECTIVES: Evaluation of the success of dental implants in mandibular narrow ridges $(\leq 5 \mathrm{~mm})$ after using bone expansion and cortical bone bending technique with a new design of bone expander.

MATERIALS AND METHODS: This clinical study was performed on a total of eight patients with mandibular narrow ridges $(\leq 5 \mathrm{~mm})$. All implants were followed for 6 months. Clinically, each patient was evaluated for pain, tenderness or discomfort, presence of swelling or infection and mobility of the implant. Also, radiographic investigations were performed for the assessment of marginal bone level, bone width and the bone density around the implant. An implant stability and assessment of the osseointegration progress evaluation was conducted using the resonance frequency analysis technique (Osstell) immediately after implant placement and after three months and after six months.

RESULTS: There was a statistically significant increase in the bone density around the implants throughout the evaluation period and there was increase in implant stability quotient after six months was statistically significant $(p=0.008)$. There were significant decreases in the mean of marginal bone level changes by time in all cases, the increase in bone width quotient after six months was statistically significant $\mathrm{p}<0.001$. CONCLUSIONS: using the newly designed star shape bone expanders as a bone expansion and bending technique, showed an adequate clinical and radiographic performance in the mandibular narrow ridges.
\end{abstract}

KEYWORDS: narrow ridges, bone expansion, implant stability.

1- Resident at Oral and Maxillofacial Surgery Department, Faculty of Dentistry, Alexandria University, Alexandria, Egypt.

2- Professor of Oral and Maxillofacial Surgery, Faculty of Dentistry, Alexandria University, Alexandria, Egypt.

*Corresponding author:

E-mail: alaaheggy@gmail.com

\section{INTRODUCTION}

Nowadays, dental rehabilitation of partially or totally edentulous regions through dental implants has become common practice with reliable long-term results (1).

However, due to bone atrophy, periodontal disease and trauma, alveolar ridges are more often compromised with horizontal deficiency, Compromised bone quality and quantity after tooth extraction always occurs. These deformities affect implant fixture placement, stability, and long-term success, preventing a proper implant treatment Implants placed in poor quality bone are often related to compromised primary stability and poor osseointegration (2).

The foundation of implant success has been attributed to their firm bone anchorage called osseointegration or functional ankylosis. It is a predictable tissue response to the placement of tooth root analogues by direct contact between living bone and implants at the light microscopical level. In order to achieve osseointegration the preparation of the bone must be done so that minimal tissue injuries produced (3).

Various surgical widening techniques have been described (4), including lateral augmentation with or without guided bone regeneration (GBR), ridge expansion osteotomy (5), ridge splitting technique with or without interpositional grafting and horizontal distraction osteogenesis $(6,7)$.
These procedures always give chances of surgical risk, postoperative morbidity and multiple long operating surgeries, exposure of the membrane or using bone grafts that could lead to infection. Thus, surgical alveolar ridge expansion was proposed as an alternative technique, where the two cortical plates are expanded to increase the width and thereby to introduce the implant with an appropriate diameter without the removal of any bone from the patient $(8,9)$.

Bone expansion can be performed by means of osteotomes and manual expanders; these are special set of instruments that were developed to form or shape bone in preparation for the placement of dental implants. They increase the width of bone for implant placement and allow immediate placement of implants in narrow ridges at the time of expansion (10).

This noninvasive way of widening narrow ridges does not require harvesting of bone, reduces operating time and postoperative morbidity, shortens the rehabilitation time, and eliminates the risk of exposure of the membrane or bone graft that could lead to infection (11).

A New design of bone expanders was introduced recently, these expanders are star shaped and they are designed to allow bone expansion with bending of the cortical bone. They provide more surface area and prevent the fracture of the alveolar bone by reducing condensation forces and load (12). 
This system is designed to push the alveolar bone to form a placement hole, providing a perfect protection to anatomical structures and reducing the need for bone grafting (12).

Currently, there are no scientific researches on these newly designed bone expanders, therefore this study is designed to evaluate their efficacy in mandibular narrow ridges.

This study proposes that this newly designed bone expanders may have similar results to conventional bone expanders.

\section{MATERIALS AND METHODS \\ 1) Study design}

Thirteen patients were selected from the Outpatient Clinic of the Oral and Maxillofacial Surgery Department, Faculty of Dentistry, Alexandria University. Patients had an atrophic mandibular edentulous ridge.

\section{Patients selection criteria}

Inclusion criteria

- Patients of both sexes, with age of 30-50 years.

- Patients with narrow mandibular ridges $(\leq 5 \mathrm{~mm})$.

- Good oral hygiene.

- Adequate inter-occlusal space at the implant site.

- Sufficient available bone to fully accommodate the implant.

\section{Exclusion criteria}

- Presence of any bony or soft tissue pathological condition at the surgical site.

- Presence of any uncontrolled systemic disease.

- Para functional habits.

- Heavy smokers.

Informed consent: All patients received explanations about the planned treatment and its potential risks and complications, and signed a written informed consent form prior to being enrolled in the study. It was also mentioned that the patient had the right of withdrawal from the study anytime without any consequences. Ethical approval for this study was obtained from the research ethics committee, Faculty of Dentistry, Alexandria University before beginning the study.

\section{2) Materials}

\section{Magic Implant}

All implants IBS (InnoBioSurg Co.,Ltd, Korea ) were made of titanium alloy with a resorbable blast media surface.

Implants were available in different sizes, lengths (7 9 - 11- 13mm) and diameters (4 - 4.5 - 5mm).

These implants had the following features; a switched platform, a tapered shape, a conical connection with hex base, single threads with new design "fin threads".

They were specially designed for self-tapping which cuts through the bone with no bone chipping while simultaneously condensing the bone, in order to optimize the achievement of primary stability in any type of bone density.

\section{The magic kit}

Contains guide drill, magic split and a star shaped bone expander.

\section{A)The pre surgical phase}

Prior to any treatment approach, every patient was evaluated regarding both dental and medical status, The preoperative data were collected and recorded in full details including name, age, gender, occupation, address, telephone number, past medical history, family history, drug history and past dental history was fulfilled. Inspection and palpation of the site of implant placement was performed, as well as adjacent and opposing teeth, adjacent structure and occlusion; a study model was casted for pre-operative assessment. A CBCT was performed to all patients to measure the width of the alveolar ridge, Planification of the implant placement and the Approximation to mandibular or mental nerve.

B) Surgical phase (Fig 1)

- All patients were operated under local anesthesia, using infiltration technique (Articaine $\mathrm{HCl}$ and Epinephrine $1: 20.000)$.

- All patients were instructed to rinse with $0.12 \%$ chlorhexidine for 2 minute.

- Full-thickness flap was performed, and extended to one tooth mesial and one tooth distal to the implant site, and slightly lingual to the crest of the ridge.

- A sharp end periosteal elevator was used to elevate the mucoperiosteal flap.

- 1.6 guide drill was used to guide the initial osteotomy for the Magic Split, Drilling was done with low speed (1000 rpm) high torque with internal irrigation with normal saline.

- The Magic split with angled hand lever was then inserted in the osteotomy site, gentle tapping was performed using the mallet until the planned depth was reached, and then the magic split was used for mesiodistal cortical bone incision.

- The 1.6 guide drill was used again to remove the mesiodistal cortical bone and form an oval shape hole.

- The star-shaped magic expander with angled hand lever was then inserted to the length of the implant, by gentle tapping using mallet until the planned depth was reached, the magic expander was used for the bone expansion with ideal condensation.

- Tapered implants were inserted using a ratchet and its adapter. The implant stability was measured by using Osstell. The SmartPeg was screwed into the internal thread of the implant, using a torque of approximately 4-6 Ncm. Then, the Osstell probe was placed in close proximity to the Smart Peg without touching it, to measure the primary stability of the implant (13). The mucoperiosteal flap was sutured, using 3-0 black silk suture (14).
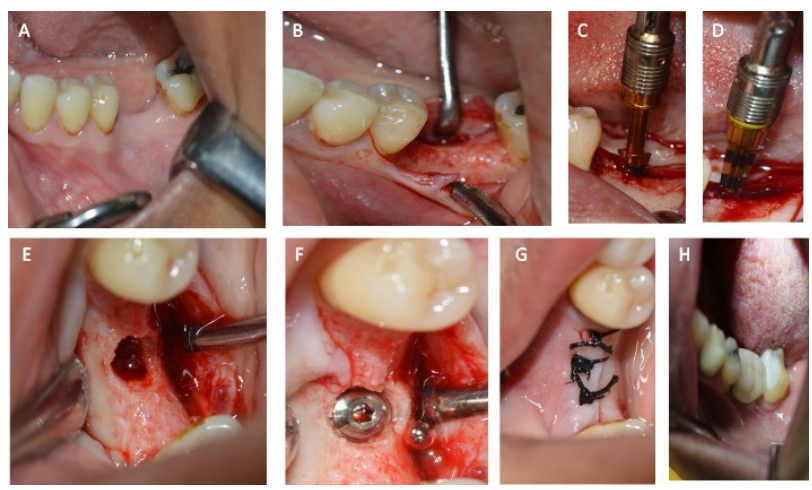

Figure (1): Case 1: (A) Photograph showing missing mandibular first molar. (B) Photograph showing reflected full Mucoperiosteal flap. (C) Magic split. (D) Magic expander. (E) Osteotomy. (F) Implant with cover screw. (G) Photograph showing the mucoperiosteal flap sutured, using 3-0 black silk suture. (H) Photograph showing the final prosthesis cemented after 3 months. 


\section{C) Post-operative phase}

All patients were instructed to apply cold packs extra-orally intermittently every 10 minute for 2 hours on the first day, Chlorhexidine $0.12 \%$ mouth wash started after the day of surgery 3 times daily for 7 days, an Antibiotic every 12 hours for 5 days and Non-steroidal anti-inflammatory drugs. Every 8 hours daily for 3 days were instructed as a postoperative medication the sutures were removed after one week post-surgically.

\section{D) Follow up phase}

Clinical evaluations were performed for each patient, immediately after implant placement and at a set of intervals, patients were evaluated for pain daily for the first week, then weekly for the first month through Visual Analogue Scale (15). Patients were evaluated for postoperative complications daily for the first week, and then weekly for the first month. A visual descriptor scale (16) was used to indicate presence/absence of edema and inflammation. any post-operative complications such as peri-implant mucositis, peri-implantitis, infection, numbness, wound dehiscence occurring at the implant site during the entire follow-up time was recorded. The depth of the peri-implant sulcus was performed by using calibrated periodontal probe with light force to avoid undue tissue damage and over extension into the healthy tissue. Measurements were taken after implant placement, at three months and at six months post-operatively (17).

The Osstell was used to measure implant stability after implant placement, at three months and at six months postoperatively $(18,19)$.

Cone beam computerized tomography (20) was performed immediately and six months post operatively (Fig 2) to assess: Bone width, marginal bone level, Bone density.
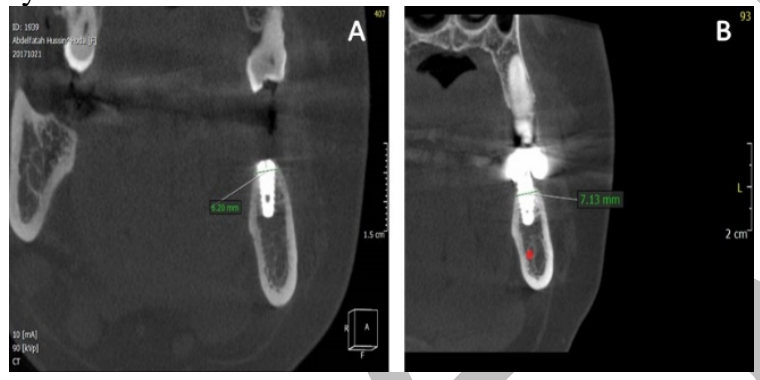

Figure (2): Radiographic evaluation of case 1: (A) immediate postoperative cone beam CT showing the implant in place. (B) Photograph showing A 6month postoperative CBCT showing the implant.

Buccolingal Bone width was measured at certain points on the CBCT preoperatively and measured immediately post operatively and after 6 months.

For Assessment of the bone density around the implant Exposure was performed using Scanora (Scanora 3DxSordex-Finland) at $10 \mathrm{MA}, 90 \mathrm{KV}$ and at a proper field of view.

- Image reconstruction was performed using a special software called “Ondemand 3D" (Ondemand3D: Cybermed, Korea) version 1.0.7. Measurements were taken as follows: The bone density apical, buccal and lingual to the implant was used as a known measurement in Hounsfield Unit (To convert from the normal units found in CT data (a typical data set ranges from 0 to 4000 pixel) you have to apply a linear transformation of the data. The equation is: $($ hu $=$ pixel_value $*$ slope + intercept $)$.

\section{E) Prosthetic phase}

After 3 months post operatively, the cover screw was removed and the healing abutment placed from 1-2 weeks.

Then, the healing abutment was removed and the abutment was tightened, a condensation silicone impression material was used to make the impression, and definitive porcelain fused to metal restorations were delivered to all patients (Fig 1).

\section{Statistical analysis}

- Statistical analysis were performed using a statistical software package SPSS.

- Data were represented as mean + standard deviation. Repeated measures analysis of variance (ANOVA) test was used to compare numeric variables within the studied group of patients.

- For categorical data, non-parametric ANOVA (Friedman's test) was performed to detect significant changes within the studied group of patients.

- Post Hoc test was done if ANOVA or Friedman tests were positive. Pearson's correlation coefficient was used to identify relations between the studied variables.

- In all tests, result was considered statistically significant if the $\mathrm{p}$ - value was less than 0.05 .

\section{RESULTS}

A total of thirteen implants were placed in eight patients (6 females and 2 males). of mean age 38 years. They were selected from the Outpatient Clinic of the Oral and Maxillofacial Surgery Department, Faculty of Dentistry, Alexandria University. Nine implants with $4 \mathrm{~mm}$ diameter $\times 11 \mathrm{~mm}$ length were placed in six patients and four implants with $4 \mathrm{~mm}$ diameter $\times 9 \mathrm{~mm}$ length were placed in two patients, and. All patients were followed up both clinically and radiographically for 6 months.

\section{1- Clinical evaluation}

Pain was evaluated postoperatively daily for the first week then weekly for the first month using the visual analogue scale. On the first postoperative days, all patients experienced mild to moderate pain at the surgical site scoring between two, and three on visual analogue scale. Postoperative tenderness and discomfort were minimal in all cases. During the follow up period, all patients felt no pain, tenderness, or discomfort after implant placement except one case that felt mild postoperative pain scoring two on visual analogue scale and moderate discomfort in the third week after implant placement. In two cases, periimplant infection with suppuration and swelling in the operated area was found; the first case was failed after three weeks of implant placement and the other was failed after 2 months. In the other cases, patients continued the follow up period without any complications, clinical signs of inflammation, swelling, numbness or peri-implant infections after implant placement or during the evaluation period.

Implant stability quotient was measured in all patients using the resonance frequency analysis technique by the Osstell TM device immediately after implant placement at three months and at six months. The data was collected and tabulated and statistical analysis was done for all patients, the change in implant stability from one interval to the subsequent visit was statistically insignificant after implant placement to the third month (p1=0.688). 
In addition the increase in implant stability from implant placement to the six month was statistically significant $\left(\mathrm{p}_{2}=0.015\right)$ and finally the increase in implant stability from 3 months to 6 months was statistically significant $\left(\mathrm{p}_{3}<0.001\right)$. The statistical analysis of implant stability scores was done for all patients in Table (1).

Table (1): Comparison between the three periods according to Ostell $(\mathrm{n}=11)$.

\begin{tabular}{|c|c|c|c|c|c|}
\hline Ostell & Immediate & $\begin{array}{c}3^{\text {rd }} \\
\text { month }\end{array}$ & $\begin{array}{c}6^{\text {th }} \\
\text { month }\end{array}$ & $\mathbf{F}$ & $\mathbf{P}$ \\
\hline $\begin{array}{l}\text { Min. - } \\
\text { Max. }\end{array}$ & $54.0-83.0$ & $\begin{array}{c}62.0- \\
80.0\end{array}$ & $\begin{array}{c}67.0- \\
84.0\end{array}$ & & \\
\hline $\begin{array}{r}\text { Mean } \pm \\
\text { SD. }\end{array}$ & $\begin{array}{c}71.73 \pm \\
9.08\end{array}$ & $\begin{array}{c}73.91 \\
\pm 5.30\end{array}$ & $\begin{array}{l}78.0 \pm \\
4.86\end{array}$ & $9.861^{*}$ & $0.008^{*}$ \\
\hline Median & 70.0 & 75.0 & 80.0 & & \\
\hline $\begin{array}{l}\text { Sig. bet. } \\
\text { Periods }\end{array}$ & \multicolumn{3}{|c|}{$\mathrm{p}_{1}=0.688, \mathrm{p}_{2}=0.015^{*}, \mathrm{p}_{3}<0.001^{*}$} & & \\
\hline
\end{tabular}

F: $F$ test (ANOVA) with repeated measures, Pairwise comparison bet. each 2 groups was done using Post Hoc Test (Bonferroni)

p: $\mathrm{p}$ values for comparing between three periods

\section{2- Radiographic evaluation}

1-Assessment of bone density of the newly formed bone:

Data were collected regarding mean peri-implant bone density values. The mean was calculated immediately postoperative as the base line and after 6 months.

In the immediate post-operative phase, the mean periimplant bone density was $689.35 \pm 129.01 \mathrm{HU}$ with a minimum recorded value of $487.14 \mathrm{HU}$ and a maximum recorded value of $864.30 \mathrm{HU}$.

In the sixth month, the mean peri-implant bone density was $974.53 \pm 160.36 \mathrm{HU}$ with a minimum recorded value of 746.97 and a maximum recorded value of $1295.70 \mathrm{HU}$. These differences were statistically significant ( $p<0.001)$. The statistical analysis of bone density scores was done for all patients in Table (2).

Table (2): Comparison between the two periods according to bone density $(n=11)$.

\begin{tabular}{|r|c|c|c|c||}
\hline Bone density & Immediate & $\mathbf{6}^{\text {th }}$ month & F & P \\
\hline Min. - & $487.13-$ & $746.97-$ & & \\
Max. & 864.30 & 1295.70 & & \\
Mean \pm & $689.35 \pm$ & $974.53 \pm$ & $7.807^{*}$ & $<0.001^{*}$ \\
SD. & 129.01 & 160.36 & & \\
Median & 717.40 & 999.28 & & \\
\hline
\end{tabular}

\section{Paired t-test}

$\mathrm{p}$ : p values for comparing between Immediate and $\mathbf{6}^{\text {th }}$ month

*: Statistically significant at $\mathrm{p} \leq 0.05$

\section{2-Assessment of the marginal bone level:}

The mean value of the marginal bone level was calculated and recorded immediate post-operative and after 6th months:

- Immediate post-operative, mean marginal bone level value was $9.07 \mathrm{~mm}$, with $\mathrm{SD} \pm 0.78 \mathrm{~mm}$.

- After 6months, mean marginal bone level value was 8.05, with SD $\pm 1.27 \mathrm{~mm}$.

- The Decrease in marginal bone level was calculated, the minimum decrease was $0.13 \mathrm{~mm}$ with mean value 1.09 $\mathrm{mm}$ and the maximum marginal bone decrease was 2.50 $\mathrm{mm}$, show that there were significant decreases in the mean of marginal bone level changes by time in all cases.

\section{3-Assessment of bone width (bone expansion):}

Buccolingal Bone width was measured from the CBCT; in certain point preoperatively, immediately after implant placement and after 6 months.

The mean bone width quotient pre surgically was $4.82 \pm 0.27 \mathrm{~mm}$. It was an increase immediately after implant placement $5.97 \pm 0.59 \mathrm{~mm}$.

The change in bone width from one interval to the subsequent visit was statistically significant between the preoperative period to the immediate period $(\mathrm{p} 1=0.001)$.

However, between the periods of immediate placement to the 6 months showed statistically insignificant in bone width (p3 < 1.000). The statistical analysis of implant stability scores was done for all patients in Table (3).

Table (3): Comparison between the three periods according to bone width $(n=11)$.

\begin{tabular}{|c|c|c|c|c|c|}
\hline $\begin{array}{l}\text { Bone } \\
\text { width }\end{array}$ & $\begin{array}{r}\text { Preoperativ } \\
\text { e }\end{array}$ & $\begin{array}{c}\text { Immediat } \\
\text { e }\end{array}$ & $\begin{array}{c}6^{\text {th }} \\
\text { month }\end{array}$ & $\mathbf{F}$ & $\mathbf{P}$ \\
\hline $\begin{array}{l}\text { Min. - } \\
\text { Max. }\end{array}$ & $4.25-5.32$ & $5.0-6.63$ & $\begin{array}{c}4.80- \\
7.13\end{array}$ & & \\
\hline $\begin{array}{l}\text { Mean } \\
\pm \text { SD }\end{array}$ & $4.82 \pm 0.27$ & $5.94 \pm 0.59$ & $\begin{array}{c}6.15 \pm \\
0.70\end{array}$ & $\begin{array}{c}20.035 \\
*\end{array}$ & $\begin{array}{l}<0.00 \\
1^{*}\end{array}$ \\
\hline $\begin{array}{r}\text { Media } \\
\mathrm{n}\end{array}$ & 4.86 & 6.15 & 6.29 & & \\
\hline $\begin{array}{r}\text { Sig. bet. } \\
\text { Periods }\end{array}$ & \multicolumn{3}{|c|}{$\mathrm{p} 1<0.001^{*}, \mathrm{p} 2<0.001^{*}, \mathrm{p} 3=1.000$} & & \\
\hline
\end{tabular}

F: $F$ test (ANOVA) with repeated measures, Pairwise comparison bet. each 2 groups was done using Post Hoc Test (Bonferroni)

p: $p$ values for comparing between three periods

$\mathbf{p}_{1}$ : $\mathrm{p}$ values for comparing between preoperative and immediate p2: $\mathrm{p}$ values for comparing betweenp preoperative and $\mathbf{6}^{\text {th }}$ month

p3: $\mathrm{p}$ values for comparing between immediate and $\mathbf{6}^{\text {th }}$ month

*: Statistically significant at $\mathrm{p} \leq 0.05$

\section{DISCUSSION}

This study was conducted to evaluate the dental implants in narrow mandibular ridge using bone expansion and bending technique.

In the present study 8 patients ( 6 females and 2 males) from 30- 50 years, Patients were selected free from any systemic diseases such as osteoporosis diabetes mellitus, heart diseases, as such conditions may complicate the surgical procedure or the healing process. Accordingly, in the year 2009, Michaeli et al (21) mentioned that the diabetes remains a relative contraindication for implant therapy.

In addition, in the year 2000, Becker et al (22) documented that osteoporosis has been considered as a risk factor for implant failures due to low bone mass and a micro-architectural deterioration of bone leading to fragility. Patients were selected with no Para functional habits as bruxism or clenching which is the most common cause of implant bone loss, Glauser et al in 2001 (23) identified a higher failure rate in the group with bruxism than among non-bruxers (41\% compared to $12 \%$ ).

In the year 1988, Koth et al (24) and Dhanrajani and Al-Rafee in 2005 (25) proposed the considerations and factors affected ossteointegration, the quantity and quality of the residual ridges and the bone width is an important criteria affect the ossteointegration, the dimension of residual ridge, surgical access and proximity of vital anatomical structure all affect the osteointegration process. 
Therefore, placement of implants surrounded by good quality bone is a prerequisite for osseointegration. As a result, a healing period of at least six months has been recommended between extraction of a tooth and subsequent implant placement (26).

In this study CBCT was performed for all patients preoperatively, corresponding to the studies conducted by Cassetta et al in 2013 (27) and Bornstein et al in 2014 (28), they reported that the use of CBCT in implant dentistry vary from preoperative analysis regarding specific anatomic considerations.

In this study surgical alveolar ridge expansion was proposed in mandibular narrow ridges by using special set of expander instrumentations that were developed to form and shape the bone in the implant placement site, Chiapasco $\mathrm{M}$, Ferrini $\mathrm{F}$ et al (29) documented that Because bone is visco-elastic, the width of the alveolar ridge can be increased by using expanders to create pressure between buccal and lingual cortical plates, in a slow organized manner Without removing of any bone from the patients, That noninvasive way of widening narrow ridges does not require harvesting of bone, reduces operating time and postoperative morbidity, shortens the rehabilitation time, and eliminates the risk of exposure of the membrane or bone graft that could lead to infection.

That agrees with Demetriades et al (30) that reported that Implant placement in atrophic ridges is a challenging procedure and often involves prior bone graft augmentation, resulting in a long time treatment plan and more surgical trauma.

In addition, this technique does not require a waiting period of 4-6 months for bone consolidation prior to implant placement and decreases the morbidity since it avoids a second surgical. However, in the year 2004, Misch (31) reported that this technique presents some limitations. It is not applicable if there is insufficient bone height for implant placement and implementing the technique on atrophic ridges $<3.0 \mathrm{~mm}$ wide may result in unfavorable bone fractures that lead to bone resorption, in cases of significant bony ridge defects and unfavorable ridge relationships.

A new design of bone expanders was introduced recently, these expanders are star shaped and they are designed to allow bone expansion with bending of the cortical bone they provide more surface area and prevent the fracture of the alveolar bone by reducing condensation forces and load.

The system is designed to push the alveolar bone to form a placement hole, providing a perfect protection to anatomical structures and reducing the need for bone grafting (12).

A single pilot drill was used, followed by atraumatic expansion of the osteotomy site using manual bone expanders to decrease surgical trauma that is mainly attributed to thermal injury of the bone. Otherwise, thermal injury may lead to osteonecrosis and possible fibrous and granulation tissue encapsulation around the implant (32).

In the year 1984, Eriksson et al (33) stated that overheating the tissues at the bone implant interface could cause bone necrosis and compromise the bone's ability to survive as well-differentiated tissue. Bone tissues are sensitive to heat at $47^{\circ} \mathrm{C}$. Rabbit tibiae heated to $50^{\circ} \mathrm{C}$ for 1 minute and $47^{\circ} \mathrm{C}$ for 5 minutes have shown a $30 \%$ to $40 \%$ bone resorption after 40 days, with bone tissue replaced by fat cells. When bone was heated to $47^{\circ} \mathrm{C}$ for 1 minute, fat cell injury and inconsistent bone injury were observed. Higher injury was reported after tissue was heated to $53^{\circ} \mathrm{C}$ for 1 minute, resulting in permanent vascular stasis and irreparable bone tissue necrosis.

Also, this is in accordance with Brisman (34) who stated that overheating of bone during preparation of the implant site can lead to bone necrosis, interfacial formation of connective tissue between the bone and the implant, loss of osseointegration and consequently loosening of the implant.

In this study maximum ridge width was $5.0 \mathrm{~mm}$, postoperative cone beam CT revealed up to $2 \mathrm{~mm}$ increase in the ridge width, This accordance with Scipioni et al (35) who stated that wherever dental implants are placed, a minimal thickness of 1 to $1.5 \mathrm{~mm}$ of bone should remain on both the buccal and the lingual/palatal aspects of the implants to ensure a successful outcome.

This study showed that the marginal bone loss occurring in the both implants right and left side did not exceed $3 \mathrm{~mm}$ during the observation period. The marginal bone loss decreased due to the preparation of the implant site and increased again due to bone remodeling during osseointegration.

Regarding to the bone density around the implant, the diagnosis of bone density around the implant is a key of success of the clinical study, the strength of the bone is directly related to bone density. Factors as the amount of bone contact, the modulous of elasticity, and axial stress contours around an implant are affected by bone density, As a consequence the treatment plan which includes implant number and size, should be modified as stress factors and bone density increases (36).

This study showed a significant change in the measurement of bone density around the implant throughout the period of evaluation which indicating successful integration that agreement with Bergkvist et al (36), Twenty-one patients received 137 implants (87 in maxillae and 50 in mandibles) Bone mineral density (BMD) was significantly correlated with bone quality classification in both arches $(\mathrm{P}<.001)$ Mean BMD was also significantly correlated with stability values $(\mathrm{P}<.001)$.

Different methods for objectively assessing primary stability have been proposed. Several studies have reported that resonance frequency analysis is a useful tool to analyze primary stability after implantation, as well as the degree of stability after osseointegration, in this study using resonance frequency analysis ostell to measure the implant stability giving a significant reading during the follow up period and that agree with Herrero-Climent et al in 2013 (37). The results of the present study imply that the resonance frequency analysis system Osstell ISQ presents "almost perfect" reproducibility and repeatability after statistical analysis by means of the intra class correlation coefficient. Therefore It can be concluded that Osstell system measurements are highly reliable regarding repeatability.

These results are in accordance with the studies performed by Le Resche et al in 2000 (38) stated that the pain following the implant placement ranged from mild to moderate scoring between 0 and 3 on visual analogue scale. The peak of pain perception occurred on day one following surgery.

In two cases, peri-implant infection with suppuration and swelling in the operated area was found, the first case was after three weeks of implant placement and the other 
was after 2 months. In the year 2012, Sakka et al (39) stated that peri implant infection seem to be one of the most important causes of early implant failure. Early signs of infection may be an indication of a much more critical result than if the same complications occur later, because of disturbance of the primary bone healing process, early infection around the implant and failure of this case could be attributed to lack of oral hygiene maintenance by the patient in spite of the instructions given to her, Early periimplant infection may have a role in preventing osseointegration.

In the other cases, patients continued the follow up period without any complications, clinical signs of inflammation, swelling or peri-implant infections after implant placement or during the evaluation period.

\section{CONCLUSION}

From the results of this study we can conclude that using the newly designed star shape bone expanders as a bone expansion and bending technique, showed an adequate clinical and radiographic performance in the mandibular narrow ridges.

\section{CONFLICT OF INTEREST}

The authors declare that they have no conflicts of interest.

\section{REFERENCES}

1. Tang YL, Yuan J, Song YL, Ma W, Chao X, Li DH. Ridge expansion alone or in combination with guided bone regeneration to facilitate implant placement in narrow alveolar ridges: a retrospective study. Clin Oral Implants Res. 2015;26:204-11.

2. Demetriades N, Park JI, Laskarides C. Alternative bone expansion technique for implant placement in atrophic edentulous maxilla and mandible. J Oral Implantol. 2011;37:463-71.

3. Branemark PI. Introduction to osseointegration. In: Branemark PI, Zarb G, Albrektsson T (eds). Tissue integrated prosthesis. Osseointegration in clinical dent. Chicago: Quintessence; 1995. p 11-7.

4. Raghavendra S, Wood MC, Taylor TD. Early wound healing around endosseous implants: A review of literature. Int J Oral Maxillofac Implants. 2005;20:425-31.

5. De Boever AL, De Boever JA. A one-stage approach for nonsubmerged implants using a xenograft in narrow ridges: report on seven cases. Int J Periodontics Restorative Dent. 2003;23:169-75.

6. Basa S, Varol A, Turker N. Alternative bone expansion technique for immediate placement of implants in the edentulous posterior mandibular ridge: A clinical report. Int J Oral Maxillofac Implants. 2004;19:554-8.

7. Elian N, Jalbout Z, Ehrlich B, Classi A, Cho SC, Al-Kahtani $\mathrm{F}$, et al. A two-stage full-arch ridge expansion technique: review of the literature and clinical guidelines. Implant Dent. 2008;17:16-23.

8. Chiapasco M, Ferrini F, Casentini P, Accardi S, Zaniboni M. Dental implants placed in expanded narrow edentulous ridges with the extension crest device. A 1-3-year multicenter follow-up study. Clin Oral Implants Res. 2006;17:265-72.

9. Cullum D. Advances in bone manipulation: Part 2. Osteomobilization for horizontal and vertical implant site development. SROMS. 2010;18:1-44.
10. Sethi A, Kaus T. Maxillary ridge expansion with simultaneous implant placement: 5-year results of an ongoing clinical study. Int J Oral Maxillofac Implants. 2000;15:491-9.

11. Demetriades N, Park JI, Laskarides C. Alternative bone expansion technique for implant placement in atrophic edentulous maxilla and mandible. $\mathrm{J}$ Oral Implantol. 2011;37:463-71.

12. IBS implant, Dream Series, H-1 drill - Suppliers of dental implant, fixture from South Korea. IBS Implant. 2010. Available at: http://ibsimplant.blogspot.com.eg/

13. Meredith N, Alleyne D, Cawley P. Quantitative determination of the stability of the implant-tissue interface using resonance frequency analysis. Clin Oral Implants Res. 1996;7:261-7.

14. Silverstein LH, Kurtzman GM. A review of dental suturing for optimal soft-tissue management. Compend Contin Educ Dent. 2005;26:163-209.

15. Le Resche L, Burgess J, Dworkin SF. Reliability of visual analog and verbal descriptor scales for "objective" measurement of temporomandibular disorder pain. J Dent Res. 2000;67:33-6.

16. Yokobe J, Kitahara M, Matsushima M, Uezono S. Preference for different anchor descriptors on visual analogue scales among Japanese patients with chronic pain. PLoS One. 2014;9:99-1.

17. Ramachandra SS, Mehta DS, Sandesh N, Baliga V, Amarnath J. Periodontal probing systems: a review of available equipment. Compend Contin Educ Dent. 2011;32:71-7.

18. Balleri P, Cozzolino A, Ghelli L, Momicchioli G, Varriale A. Stability measurements of osseointegrated implants using Osstell in partially edentulous jaws after 1 year of loading: a pilot study. Clin Implant Dent Relat Res. 2002;4:128-32.

19. Bischof M, Nedir R, Szmukler-Moncler S, Bernard JP, Samson J. Implant stability measurement of delayed and immediately loaded implants during healing. Clin Oral Implants Res. 2004;15:529-39.

20. Georgescu CE, Mihai A, Didilescu AC, Moraru R, Nimigean V, Nimigean VR, et al. Cone beam computed tomography as a method of quantitative and qualitative analysis of alveolar crest in the mandibular area. Rom J Morphol Embryol. 2010;51:713-7.

21. Michaeli E, Weinberg I, Nahlieli O. Dental implants in the diabetic patient: systemic and rehabilitative considerations. Quintessence Int. 2009;40:639-45.

22. Becker W, Hujoel PP, Becker BE, Willingham $\mathrm{H}$. Osteoporosis and implant failure: an exploratory casecontrol study. J Periodontol. 2000;71:625-31.

23. Glauser R, Rée A, Lundgren A, Gottlow J, Hämmerle CH, Schärer P. Immediate occlusal loading of Brånemark implants applied in various jawbone regions: a prospective, 1-year clinical study. Clin Implant Dent Relat Res. 2001;3:204-13.

24. Koth DL, McKinmey RV, Steflik DE, Davis QB. Clinical and statistical analysis of human clinical trials with single crystal aluminum oxide endosteal dental implant: Five year results. J Prosthet Dent. 1988;60:226-34. 
25.Dhanrajani PJ, Al-Rafee MA. Single-tooth implant restorations: A retrospective study. Implant Dent. 2005;14:125-30.

26. Sakka S, Coulthard P. Bone quality: a reality for the process of osseointegration. Implant Dent. 2009;18:480-5.

27. Cassetta M, Sofan AA, Altieri F, Barbato E. Evaluation of alveolar cortical bone thickness and density for orthodontic mini-implant placement. J Clin Exp Dent. 2013;5:245-52.

28. Bornstein MM, Scarfe WC, Vaughn VM, Jacobs R. Cone beam computed tomography in implant dentistry: a systematic review focusing on guidelines, indications, and radiation dose risks. Int $\mathrm{J}$ Oral Maxillofac Implants. 2014;29:55-77.

29. Chiapasco M, Ferrini F, Casentini P, Accardi S, Zaniboni M. Dental implants placed in expanded narrow edentulous ridges with the Extension Crest device. A 1-3-year multicenter follow-up study. Clin Oral Implants Res. 2006;17:265-72.

30. Demetriades N, Park JI, Laskarides C. Alternative bone expansion technique for implant placement in atrophic edentulous maxilla and mandible. J Oral Implantol. 2011;37:463-71.

31. Misch CM. Implant site development using ridge splitting techniques. Oral Maxillofac Surg Clin North Am. 2004;16:65-74.

32.Hahn J. Clinical uses of osteotomes. J Oral Implantol. 1999;25:23-9.

33. Eriksson AR, Alberktsson T, Magnusson B. Assessment of bone viability after heat trauma. A histological, histochemical, and vital microscopic study in the rabbit. Scand J Plast Reconstr Surg. 1984;18:261-8.
34. Brisman DL. The effect of speed, pressure, and time on bone temperature during the drilling of implant sites. Int $\mathrm{J}$ Oral Maxillofac Implants. 1996;11:35-7.

35. Scipioni A, Bruschi GB, Calesini G, Bruschi E, De Martino $\mathrm{C}$. Bone regeneration in the edentulous ridge expansion technique: Histologic and ultrastructural study of 20 clinical cases. Int J Periodontics Restorative Dent. 1999;19:269-77.

36. Bergkvist G, Koh KJ, Sahlholm S, Klintström E, Lindh C. Bone density at implant sites and its relationship to assessment of bone quality and treatment outcome. Int $\mathrm{J}$ Oral Maxillofac Implants. 2010;25:321-8.

37. Herrero-Climent M, Santos-García R, Jaramillo-Santos R, Romero-Ruiz MM, Fernández-Palacin A, Lázaro-Calvo P, et al. Assessment of Osstell ISQ's reliability for implant stability measurement: a cross-sectional clinical study. Med Oral Patol Oral Cir Bucal. 2013;18: 877-82.

38. Le Resche L, Burgess J, Dworkin SF. Reliability of visual analog and verbal descriptor scales for "objective" measurement of temporomandibular disorder pain. J Dent Res. 2000;67:33-6.

39. Sakka S, Baroudi K, Nassani MZ. Factors associated with early and late failure of dental implants. J Investig Clin Dent. 2012;3:258-61.

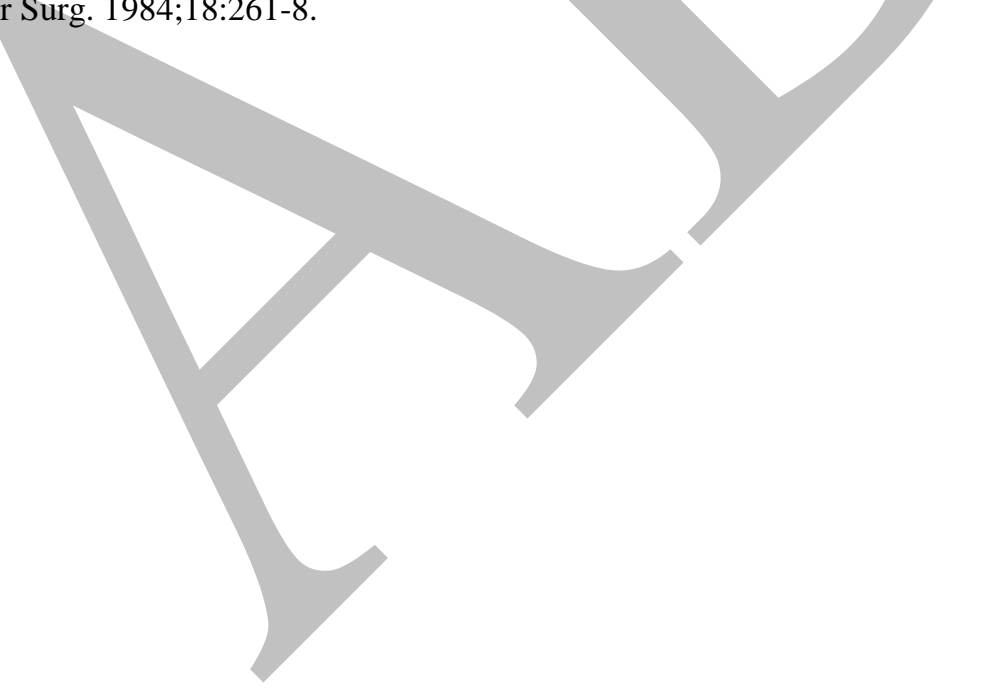

